

This is the author manuscript accepted for publication and has undergone full peer review but has not been through the copyediting, typesetting, pagination and proofreading process, which may lead to differences between this version and the Version of record. Please cite this article as doi:10.1002/ jum.14616.

This article is protected by copyright. All rights reserved. 


\section{Fetal Intelligent Navigation Echocardiography (FINE) Detects $98 \%$ of Congenital Heart Disease}

\section{Short Running Title: FINE Detection of Congenital Heart Disease}

Lami Yeo, MD ${ }^{1,2,3}$, Suchaya Luewan, MD ${ }^{1,4}$, Roberto Romero, MD, D.Med.Sci. ${ }^{1,5,6,7}$

${ }^{1}$ Perinatology Research Branch, Program for Perinatal Research and Obstetrics, Division of Intramural Research, Eunice Kennedy Shriver National Institute of Child Health and Human Development, NIH, Bethesda, MD and Detroit, MI, USA

${ }^{2}$ Detroit Medical Center, Hutzel Women's Hospital, Detroit, MI, USA

${ }^{3}$ Department of Obstetrics and Gynecology, Wayne State University School of Medicine, Detroit, MI, USA

${ }^{4}$ Department of Obstetrics and Gynecology, Chiang Mai University, Chiang Mai, Thailand ${ }^{5}$ Department of Obstetrics and Gynecology, University of Michigan, Ann Arbor, MI, USA ${ }^{6}$ Department of Epidemiology and Biostatistics, Michigan State University, East Lansing, MI, USA

${ }^{7}$ Center for Molecular Medicine and Genetics, Wayne State University, Detroit, MI, USA

\section{Address correspondence to:}

Lami Yeo, MD and Roberto Romero, MD, D. Med. Sci.

Perinatology Research Branch, NICHD, NIH, DHHS

Hutzel Women's Hospital

3990 John R, 4 Brush

Detroit, MI 48201, USA

Telephone (313) 993-2700

Fax: (313) 993-2694

E-mail Address: 1yeo@med.wayne.edu and prbchiefstaff@med.wayne.edu

\section{Manuscript Category: Original Research}




\section{ABSTRACT}

Objective: Fetal Intelligent Navigation Echocardiography (FINE) is a novel method that automatically generates and displays nine standard fetal echocardiography views in normal hearts by applying intelligent navigation technology to spatiotemporal image correlation (STIC) volume datasets. The main objective was to determine the sensitivity and specificity of FINE in the prenatal detection of congenital heart disease (CHD).

Methods: A case-control study was conducted in 50 fetuses with a broad spectrum of CHD (cases) and 100 fetuses with normal hearts (controls) in the second and third trimesters. Using four-dimensional ultrasound with STIC technology, volume datasets were acquired. After all identifying information was removed, the datasets were randomly distributed to a different investigator for analysis using FINE. The sensitivity and specificity for the prenatal detection of $\mathrm{CHD}$, as well as positive and negative likelihood ratios (LR) were determined.

Results: The diagnostic performance of FINE for the prenatal detection of CHD was: sensitivity 98\% (49/50), specificity 93\% (93/100), positive LR of 14, and negative LR of 0.02. Among cases with confirmed CHD, the diagnosis based upon FINE completely matched the final diagnosis in $74 \%(37 / 50)$, minor discrepancies were seen in $12 \%(6 / 50)$, and major discrepancies were seen in $14 \%(7 / 50)$.

Conclusions: We present for the first time the sensitivity and specificity of the FINE method in fetuses with normal hearts and CHD in the second and third trimesters. Since FINE identifies a broad spectrum of CHD with $98 \%$ sensitivity, this method could be used prenatally to screen for and diagnose CHD. 
Keywords: 4D; cardiac; fetal heart; prenatal diagnosis; STIC; ultrasound

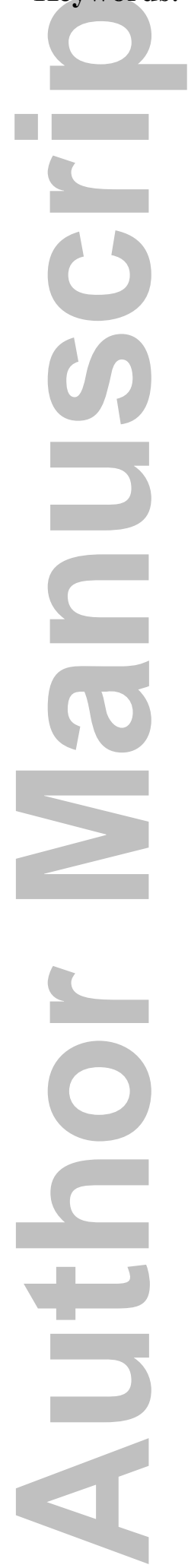




\section{$\underline{\text { INTRODUCTION }}$}

Congenital heart defects (CHD) are the most common birth defect, ${ }^{1}$ as well as the leading cause of infant morbidity and mortality from congenital malformations. ${ }^{2}$ Screening of all pregnancies is required to detect CHD prenatally, since up to $90 \%$ of cases occur in pregnancies without high risk features. ${ }^{3}$ Yet, the prenatal detection of CHD has remained challenging, with the sensitivity of ultrasound ranging from $15-39 \% .^{4-12}$ This has been attributed mainly to operator skill and expertise ${ }^{13-18}$ however, other factors include the complex anatomy, motion, and small size of the fetal heart. The lack of prenatal identification of CHD is associated with adverse consequences for the neonate, including abnormal neurological development, and even death. ${ }^{19-22}$ In contrast, the prenatal diagnosis of specific cardiac anomalies improves the preoperative condition, ${ }^{23-27}$ pre-surgical mortality rate, ${ }^{28-30}$ survival after surgery, ${ }^{19,23,31,32}$ and long-term neurocognitive function and outcome. ${ }^{33,34}$

Four-dimensional (4D) ultrasound with spatiotemporal image correlation (STIC) facilitates fetal cardiac examination ${ }^{35-66}$ and has the potential to increase the detection rate of $\mathrm{CHD},{ }^{35,67,68}$ leading some to propose its clinical application in both prenatal cardiac screening and diagnosis of CHD. ${ }^{69-75}$ STIC technology allows the acquisition of a volume dataset of the fetal heart, in which cardiac planes may be extracted and displayed in any orientation. ${ }^{43,55}$ However, the use of software to perform manual navigation ${ }^{76}$ through such volume datasets is time consuming, highly operator dependent, and requires a thorough knowledge of cardiac anatomy. ${ }^{77-79}$ As a result, this process is difficult and impractical, especially when the fetal heart is abnormal. ${ }^{80}$ 
Fetal intelligent navigation echocardiography (FINE) is a novel method developed recently that automatically generates and displays nine standard fetal echocardiography views in normal hearts by applying 'intelligent navigation' technology to STIC volume datasets. $^{66,76-80}$ Therefore, such method can simplify examination of the fetal heart and reduce operator dependency. Indeed, studies have reported that FINE applied to STIC volume datasets can successfully generate nine fetal echocardiography views in $96-100 \%{ }^{79}$ and $98-100 \%{ }^{77,78}$ of normal hearts in the second and third trimesters. As a result, FINE has been suggested as a method to screen for CHD. ${ }^{78,79}$ However, to be clinically useful, a screening test should demonstrate both good specificity and sensitivity. ${ }^{81}$ Therefore, we conducted this study to determine the sensitivity and specificity of FINE in the prenatal detection of CHD.

\section{MATERIALS AND METHODS}

\section{Subjects}

A case-control study of 150 pregnant women having a singleton fetus with a normal heart (100 controls) or confirmed CHD (50 cases) in the second or third trimester was conducted. Patients were examined at the Detroit Medical Center/Wayne State University and the Perinatology Research Branch of NICHD, NIH, DHHS. All women had been enrolled in research protocols approved by the Institutional Review Board of NICHD, NIH, and by the Human Investigation Committee of Wayne State University. All participants provided written informed consent for the use of sonographic images for research purposes. The final diagnosis of $\mathrm{CHD}$ was confirmed by neonatal echocardiography and/or other ancillary diagnostic procedures (e.g. surgery, cardiac 
catheterization, autopsy). In cases when such information was not available, the final diagnosis of CHD was based upon the results of fetal echocardiography performed by an expert.

\section{Spatiotemporal image correlation (STIC) volume datasets}

Using STIC technology, sonographic volume datasets of the fetal heart containing gray-scale information were acquired from a four-chamber view by transverse sweeps through the fetal chest in patients examined at our unit. The acquisition time ranged from 10 to 12.5 seconds, depending on fetal motion, and the acquisition angle ranged between 20 and 40 degrees, depending on gestational age.

Volume datasets were selected for analysis using FINE if they met the following criteria: 1) fetal spine located between the 4- and 8-o'clock positions (reducing the possibility of shadowing from the ribs or spine); 2) upper fetal mediastinum and stomach included and visible in the STIC volume; 3) adequate image quality such that fetal anatomy could be visualized; and 4) absence of excessive motion artifacts that could distort anatomic structures. Only a single STIC volume per patient was analyzed.

The following seven major types of CHD were the focus of this study: 1) complete transposition of the great vessels; 2) tetralogy of Fallot; 3) coarctation of the aorta; 4) pulmonary atresia with intact ventricular septum; 5) double outlet right ventricle; 6) hypoplastic left heart; and 7) atrioventricular canal defect. This is justified because such CHD are difficult to diagnose, prenatal diagnosis improves outcome, and some represent a neonatal emergency. However, a broad spectrum of CHD types overall was included to evaluate the diagnostic performance of FINE. 


\section{Training on the FINE method}

One of the investigators (SL) who had no prior familiarity with the FINE method underwent formal training by the same investigators who invented FINE. Such training occurred in a 2-day period and included: 1) attending didactic lectures on FINE; and 2) review of 16 previously acquired STIC volume datasets of normal fetal hearts using the FINE method. Specifically, the following features of FINE were reviewed during the training period (Table 1): ${ }^{.55,76,77,79} 1$ ) intelligent navigation technology; 2) STICLoop ${ }^{\mathrm{TM}}$ and STICLoop criteria; 3) Anatomic Box ${ }^{\circledR}$ (learning how to identify and mark anatomical structures of the fetal heart); 4) diagnostic planes; 5) automatic labeling and its features; 6) Virtual Intelligent Sonographer Assistance (VIS-Assistance ${ }^{\circledR}$ ) and its advantages in providing additional information, as well as how to perform double and triple VISAssistance; ${ }^{80}$ and 7) intelligent and marking alerts. Moreover, the same investigator was provided a written manual on FINE and underwent a practical session on how to technically use the system (e.g. review of buttons and screens). It is noteworthy that during the training period, no STIC volumes of CHD cases were reviewed using the FINE method.

\section{Evaluation of STIC volume datasets by FINE}

After all identifying information was removed from the 150 STIC volume datasets, they were randomly distributed to the trained investigator for analysis using the FINE method. Such investigator did not acquire any of the STIC volumes, and was blinded to the fetal cardiac diagnosis. To perform the analysis, the STIC volumes were imported into a 
software system (5D Heart/Fetal Intelligent Navigation Echocardiography; Version 2015.09.30; Samsung Healthcare, Seoul, Korea) that was installed onto a laptop computer. The investigator employed all of the features of FINE (e.g. automatic labeling) when interrogating each STIC volume dataset to assist in determining whether the fetal heart was normal or abnormal, and to make a specific diagnosis. When using the Anatomic Box tool, if marking any of the anatomical structures of the fetal heart seemed difficult, the structure was absent (e.g. crux of the heart), or the structure was not in its usual location, the investigator utilized best judgment and estimated the location for marking.

For each STIC volume, VIS-Assistance videoclips were observed in their entirety for all nine fetal echocardiography views since this feature of FINE: ${ }^{76,77} 1$ ) improves the success of obtaining the fetal echocardiography view of interest; 2) allows operatorindependent sonographic navigation and exploration of surrounding structures in the diagnostic plane (i.e. a 'virtual' sonographer); and 3) can show the appropriate azimuth. Written callouts (e.g. "move cephalad") appear at the top of each VIS-Assistance videoclip to inform the operator of the purpose or action of the navigational movements which are occurring automatically. This brings organization to the videoclip and allows operators to use the callouts to target their navigation.

In four cardiac VIS-Assistance views (three vessels and trachea, left ventricular outflow tract, short-axis view of great vessels/right ventricular outflow tract and abdomen/stomach) for normal hearts, we pre-specified that certain anatomical structures should also be visualized in order to consider the VIS-Assistance as being successful in depicting the echocardiography view; this has been reported elsewhere. ${ }^{77,78}$ 
Using the FINE method, the investigator initially determined whether the fetal heart was normal or abnormal, and then recorded the following information, respectively:

- Normal heart: 1) fulfillment of all nine STICLoop criteria; 2) appearance of intelligent and/or marking alerts; 3) success rate of generating each of the nine echocardiography views using diagnostic planes and/or VIS-Assistance.

Abnormal heart (CHD): 1) fulfillment of all nine STICLoop criteria; 2) appearance of intelligent and/or marking alerts; 3) frequency of abnormal echocardiography views (out of nine); 4) which echocardiography views were abnormal and a description of the findings (e.g. ventricular septal defect); 5) whether diagnostic planes and/or VIS-Assistance views were abnormal; 6) use of the double or triple VIS-Assistance technique; 7) correct or incorrect labeling of anatomical structures; 8) summary of individual findings (e.g. overriding aorta) and the final presumptive diagnosis (e.g. tetralogy of Fallot).

The sensitivity and specificity of FINE for the prenatal detection of CHD, as well as positive and negative likelihood ratios were determined. Finally, among cases with confirmed CHD, the degree of concordance with the diagnosis based upon the FINE method was categorized as follows: 1) category A: complete agreement; 2) category B:

minor discrepancies in the diagnosis; and 3) category $\mathrm{C}$ : major discrepancies in the diagnosis.

\section{$\underline{\text { RESULTS }}$}

A total of 150 STIC volume datasets (100 controls and 50 cases) were evaluated using the FINE method. The median gestational age at the time of STIC volume 
acquisition was 25 (interquartile range, 22 - 29) weeks. However, STIC volumes were obtained from 16 to 37 weeks of gestation, with $36 \%(54 / 150)$ of fetuses being in the third trimester.

\section{Normal Fetal Hearts Evaluated by FINE}

STICLoop criteria

All 100 STIC volumes of normal hearts were initially evaluated by STICLoop criteria (Table 1). Seven of the nine criteria were met $95-99 \%$ of the time. For example, in $99 \%(99 / 100)$ of STIC volumes, the upper mediastinum and stomach were included within the volume and clearly visible. However, approximately $20 \%$ of the STIC volumes of normal hearts did not meet the following STICLoop criteria: 1) minimal or absent shadowing $(21 \% ; n=21)$; and 2$)$ minimal or no motion artifacts observed in the STICLoop $(23 \% ; n=23)$. Therefore, the investigator recorded that $23 \%$ of such STIC volumes contained motion artifacts.

\section{Intelligent and marking alerts}

While marking anatomical structures of the normal fetal heart within the STIC volume (using the feature Anatomic Box), an intelligent alert automatically appeared in $27 \%(27 / 100)$ : 1) breech alert in $18 \%(\mathrm{n}=18) ; 2)$ possible drifting spine alert in $5 \%(\mathrm{n}=5)$; and 3) spine location alert in $4 \%(n=4)$. Therefore, $18 \%$ of the fetuses were in an original breech presentation so that the cardiac apex was originally pointing to the right side of the monitor screen. The spine location alert appeared in only $4 \%$ of the volumes, and such alert was automatically activated during the marking process because the fetal spine in the STIC volume was located in a position other than between 5- and 7-o'clock: 1) 7- to 8- 
o'clock in 75\% $(n=3)$ and 2) 8-o'clock in 25\% $(n=1)$. Therefore, 96 STIC volumes had a fetal spine located at 5, 6, or 7-o'clock. Each time the spine location alert was activated, three marking alerts (pulmonary valve, superior vena cava, and transverse aortic arch) appeared next in sequence. These marking alerts "informed" the investigator (through captions and a movie) that fetal anatomical structures for marking (e.g. superior vena cava) could be in a different location than expected, since the fetal spine was not located between the 5- and 7-o'clock positions.

\section{Success rates of generating fetal echocardiography views}

For the 100 normal hearts, the FINE method was able to successfully generate nine fetal echocardiography views using: 1) diagnostic planes in 94-100\% of cases; 2) VISAssistance in $100 \%$ of cases; and 3) a combination of diagnostic planes and/or VISAssistance in $100 \%$ of cases (Table 2). Figure 1 and Video 1 show an example of nine normal cardiac diagnostic planes in a single template with the additional feature of automatic labeling through intelligent navigation.

\section{Congenital Heart Disease Cases Evaluated by FINE}

Of the 50 cases, the main categories of CHD included (Table 3): 1) conotruncal anomalies $(42 \% ; n=21) ; 2)$ left heart anomalies $(20 \% ; n=10) ; 3)$ right heart anomalies $(16 \% ; n=8) ; 4)$ complex cardiac defects $(12 \% ; n=6) ;$ and 5$)$ septal defects $(10 \% ; n=5)$.

\section{STICLoop criteria}

All STIC volumes of CHD were initially evaluated by STICLoop criteria (Table 1).

Two of the nine criteria were met $98 \%$ of the time. For example, $98 \%(98 / 100)$ of the STIC volumes included the upper mediastinum and stomach, which were clearly visible. 
However, $50 \%(25 / 50)$ of the STIC volumes of CHD contained motion artifacts. Moreover, the investigator recorded that 20\% (10/50) and 26\% (13/50) of CHD volumes were characterized by inadequate image quality and shadowing, respectively.

\section{Intelligent and marking alerts}

For CHD, while marking anatomical structures of the fetal heart within the STIC volume (using the feature Anatomic Box), an intelligent alert automatically appeared in $42 \%(21 / 50): 1)$ spine location alert in $20 \%(n=10) ; 2)$ breech alert in $12 \%(n=6)$; and 3$)$ possible drifting spine alert in $10 \%(n=5)$. Therefore, $12 \%$ of the fetuses were in an original breech presentation so that the cardiac apex was originally pointing to the right side of the monitor screen. The spine location alert was automatically activated during the marking process because the fetal spine in the STIC volume was located in a position other than between 5- and 7-o'clock: 1) 7- to 8-o'clock in 50\% (n=5); 2) 4- to 5-o'clock in 30\% $(n=3)$; and 3) 4-o'clock in 20\% (n=2). For each spine location alert activated, three marking alerts (pulmonary valve, superior vena cava, and transverse aortic arch) appeared next in sequence.

\section{Abnormal fetal echocardiography views generated by FINE}

Eighty percent (40/50) of the STIC volumes of CHD had six to nine abnormal fetal echocardiography views (diagnostic planes and/or VIS-Assistance) (Figure 2 and Figure 3; Video 2 and Video 3): 1) nine abnormal views ( $8 \% ; n=4) ; 2)$ eight abnormal views (42\%; $\mathrm{n}=21)$; 3) seven abnormal views $(16 \% ; \mathrm{n}=8)$; and 4) six abnormal views $(14 \% ; \mathrm{n}=7)$. Therefore, of all the CHD cases, approximately half of them had eight abnormal fetal 
echocardiography views generated by FINE, making it highly likely that an operator would recognize the heart to be abnormal.

Of all the cases, 96\% (48/50) and 94\% (47/50) had an abnormal five-chamber view and left ventricular outflow tract view via FINE, respectively, making these the most frequent abnormal fetal echocardiography views in our study. In contrast, only $10 \%(5 / 50)$ of CHD cases had an abnormal vena cava view.

\section{VIS-Assistance and automatic labeling}

When implementing VIS-Assistance for the CHD cases, the following advantages were noted (Table 4): 1) depicted cardiac abnormalities when the diagnostic plane appeared normal; 2) provided further diagnostic information even when the diagnostic plane was abnormal (Figure 4 and Video 4); 3) changed a suspected abnormal fetal echocardiography view to one that was interpreted as normal; and 4) improved the success of obtaining the fetal echocardiography view of interest when this was not initially obtained via the diagnostic plane.

To gain further assistance in determining the CHD diagnosis and obtaining more information, the investigator employed double VIS-Assistance (Table 1) in 56\% (28/50) of the STIC volumes for one to three fetal echocardiography views. On the other hand, triple VIS-Assistance (Table 1) was activated for only $10 \%(5 / 50)$ of the STIC volumes for one to two fetal echocardiography views.

It is noteworthy that even though the fetal cardiac anatomy was abnormal for all 50 cases, the FINE method was able to automatically generate the correct labeling of 
anatomical structures (atrial and ventricular chambers, great vessels, venae cavae, and stomach) for all nine fetal echocardiography views in $74 \%(37 / 50)$ of cases.

\section{Diagnostic Performance of FINE}

The overall sensitivity, specificity, positive and negative likelihood ratios of FINE for the prenatal detection of CHD was 98\% (49/50), 93\% (93/100), 14, and 0.02 , respectively. The seven false-positive diagnoses included: 1) six fetuses suspected to have ventricular septal defects (gestational ages ranged from 19 to 31 weeks); and 2) one fetus with a suspected cardiac tumor in the right ventricle (29 weeks of gestation). The single false-negative case was a fetus examined by FINE at 26 weeks of gestation who was later diagnosed with pulmonary artery branch stenosis and a small secundum atrial septal defect in the neonatal period.

Complete concordance (category A) or a minor discrepancy (category B) between the diagnosis based on FINE and the final CHD diagnosis occurred in $86 \%(43 / 50)$ of cases: 1) complete concordance $(54 \% ; n=27)$; and 2$)$ minor discrepancy $(32 \% ; n=16)$. All of the discordant diagnoses in category B were related to: 1) secundum atrial septal defect $(75 \% ; n=12) ; 2)$ ventricular septal defect $(19 \% ; n=3) ; 3)$ left superior vena cava $(19 \%$; $\mathrm{n}=3)$; and 4) primum atrial septal defect $(6 \% ; n=1)$. Major differences (category C) between the FINE and final CHD diagnoses occurred in only $14 \%(n=7)$ of cases (Table 5).

It is noteworthy that when we excluded from category B cases in which the only discrepancy between the FINE diagnosis and the final CHD diagnosis was a secundum atrial septal defect, then 10 cases would be re-classified into category A with the following 
new classification results: 1) complete concordance $(74 \% ; n=37) ; 2)$ minor discrepancy $(12 \% ; n=6)$; and 3$)$ major discrepancy $(14 \% ; n=7)$. Such re-classification is justified because the diagnosis of a secundum atrial septal defect is almost nonexistent in the prenatal period. ${ }^{82}$

\section{DISCUSSION}

\section{Principal findings of the study}

After applying the FINE method to STIC volume datasets acquired with gray-scale information in second and third trimester fetuses with normal and abnormal hearts: 1) the sensitivity, specificity, positive and negative likelihood ratios of FINE for the prenatal detection of CHD was 98\%,93\%, 14, and 0.02 respectively; 2) among cases with confirmed CHD, the diagnosis based upon FINE completely matched the final diagnosis in $74 \%$, minor discrepancies were seen in $12 \%$, and major discrepancies were seen in $14 \% ; 3$ ) $80 \%$ of the CHD cases had six to nine abnormal fetal echocardiography views out of nine, making it highly likely that the heart would be recognized as abnormal; 4) automatic labeling of anatomical structures in all nine fetal echocardiography views was correct in $74 \%$ of CHD cases; and 5) nine fetal echocardiography views were generated successfully in normal hearts using diagnostic planes in $94-100 \%$ of cases, VIS-Assistance in $100 \%$ of cases, and a combination of diagnostic planes and/or VIS-Assistance in $100 \%$ of cases.

\section{Performance of 4D sonography with STIC in the prenatal detection of CHD}

At the time of its original conception and development, we proposed using the FINE method as an aid to examine the fetal heart in the population at large, rather than to diagnose specific CHD. ${ }^{77}$ Indeed, we had speculated that for some types of CHD, the FINE 
method may not be useful or applicable (e.g. hypoplastic left heart, atrioventricular canal defect). ${ }^{77}$ However, since that time we have gained considerable experience in the application of FINE and color Doppler FINE to a broad spectrum of CHD types, ${ }^{66,77,80}$ and concluded that such technology is both successful and informative. For example, in a case of fetal dextrocardia and situs solitus with complex CHD, FINE was invaluable in diagnosing multiple abnormalities and defining complex anatomic relationships, which had been very difficult to do using real-time echocardiography. ${ }^{80}$

However, for a test to be clinically useful it should demonstrate both high specificity and sensitivity. As a result, we set out to determine the diagnostic performance of FINE, and report for the first time herein that there is $98 \%$ sensitivity and $93 \%$ specificity for the prenatal detection of a broad spectrum of CHD. This outcome was obtained despite the fact that approximately $20 \%$ of STIC volumes of normal hearts had shadowing present, or contained motion artifacts. Moreover, STIC volumes of CHD were characterized by inadequate image quality, shadowing, or motion artifacts in $20 \%, 26 \%$, and $50 \%$ of cases, respectively. Therefore, not all the volumes analyzed in this study were ideal or optimal. Recently, an electronic matrix 4D probe has been developed which allows a marked reduction in the STIC volume acquisition time (which could lead to less motion artifacts), as well as improved image resolution in the B plane. ${ }^{55,83}$ Such electronic STIC volumes have been shown to be of more significant optimal diagnostic quality compared to conventional STIC volumes. ${ }^{84}$ Therefore, this new STIC technology could be advantageous for the FINE method. 
Likelihood ratios summarize how many times more (or less) likely patients with the disease are to have that particular result than patients without the disease. ${ }^{85}$ The further likelihood ratios are from 1 , the stronger the evidence for the presence or absence of disease. Indeed, likelihood ratios $>10$ and $<0.1$ are considered to provide strong evidence to rule in or rule out diagnoses, respectively, in most circumstances. ${ }^{85,86}$ Thus, in the current study, the positive (14) and negative likelihood ratios (0.02) indicate that results of the FINE method have a large effect on increasing or decreasing, respectively, the probability of the presence of CHD.

Prior investigators have examined the diagnostic performance of 4D sonography with STIC by using a display modality ${ }^{87}$ or manual navigation (retrieval and display of relevant cardiac diagnostic planes by interrogating volume datasets). ${ }^{70,72-74}$ Bennasar et al. used the multiplanar view to analyze STIC volumes of normal and abnormal fetal hearts, and reported an overall sensitivity and specificity of $94.9 \%(166 / 175)$ and $88.1 \%$ $(141 / 160)$, respectively. ${ }^{72}$ STIC volumes had been acquired with both gray-scale and color Doppler information. In a multi-center study of seven centers with expertise in 4D ultrasound of the fetal heart, 90 STIC volume datasets of normal $(n=45)$ or abnormal fetal hearts $(\mathrm{n}=45)$ acquired at 18-26 gestational weeks using B-mode or color Doppler sonography were blindly evaluated by all centers. ${ }^{73}$ The approach used to analyze the volumes was left to the discretion of each center. Overall, the median (range) sensitivity and specificity for the identification of fetuses with CHD were 93\% (77-100\%) and 96\% $(84-100 \%))^{73}$ Years ago, our team used tomographic ultrasound imaging (TUI) in combination with B-mode STIC volume datasets to diagnose CHD, and reported a 
sensitivity and specificity of $85.7 \%(12 / 14)$ and $100 \%(101 / 101)$, respectively. ${ }^{87}$ However, such study performance was based on only 14 cases with CHD. Paladini et al. investigated whether fourteen sonologists could detect major abnormalities of the outflow tracts by reviewing the A plane of 16 normal and 10 abnormal STIC volume datasets. ${ }^{70}$ The sensitivity and specificity were reported as $83 \%$ and $87 \%$, respectively. The individual diagnostic accuracy ranged from $66-100 \%$ (median $85.5 \%) .{ }^{70}$ In contrast, Adriaanse et al. evaluated the clinical accuracy of 4D ultrasound with STIC in a telemedicine setting. ${ }^{74}$ Ten STIC volumes from the second trimester were analyzed by 3 different observers using any desired post-processing modality (e.g. sectional planes, rendering, TUI). The authors concluded that while STIC by telemedicine is promising, it was not accurate enough for exclusive use in clinical decision making regarding treatment, prognosis, etc. ${ }^{74}$

Taken together, while most of these studies reported high sensitivity and specificity in the detection of CHD, STIC volume analysis required manual standardization or manipulation of the dataset and reference planes by the operator, or was dependent on the TUI display. Yet, operator dependency is reported to be the main problem when STIC volumes are analyzed. ${ }^{67}$ On the other hand, the FINE method substantially decreases the number of steps required to obtain echocardiography views, making this method less operator dependent and considerably simplifying the fetal cardiac examination. ${ }^{77}$ The sonologist is only required to mark anatomical structures of the fetal heart within the STIC volume dataset, triggering intelligent navigation technology and resulting in the successful generation of nine echocardiography views automatically (this occurred in $100 \%$ of normal hearts via a combination of diagnostic planes and/or VIS-Assistance for the study herein). 
For CHD cases analyzed using FINE, abnormal cardiac anatomy was evident in multiple echocardiography views simultaneously. A summary of the characteristics of the FINE method that are fundamental in determining whether the fetal heart is abnormal or not, and in determining the type of CHD are described in Table 4.

\section{Comparisons between FINE and final diagnoses}

There were seven false-positive diagnoses of ventricular septal defects based upon FINE, which would not have had a major impact on clinical outcome. Similarly, Bennasar et al. reported that $52 \%(10 / 19)$ of their false-positive diagnoses from STIC echocardiography were ventricular septal defects. ${ }^{72}$ The accurate prenatal detection of ventricular septal defects can be influenced by both the location and size of the defect, as well as drop-out artifacts. It is possible that if STIC volumes had been obtained with color or power Doppler information and analyzed by FINE (i.e. color Doppler FINE) ${ }^{66}$ in the current study, the number of false-positive diagnoses would have been reduced.

Among cases with confirmed CHD, the diagnosis based upon FINE completely matched the final diagnosis in $74 \%$, minor discrepancies were seen in $12 \%$, and major discrepancies were seen in $14 \%$. Such results are very similar to a different study in which the authors examined the concordance of prenatal and postnatal echocardiograms

performed by specialized pediatric cardiologists in a large referral center. ${ }^{88}$ Overall, the prenatal diagnosis precisely matched the postnatal diagnosis in $69.8 \%$, minor discrepancies were seen in $14.2 \%$, and major differences were seen in $16 \%$ of cases. Similarly, among cases with confirmed CHD, Bennasar reported that using STIC echocardiography, there was absolute concordance with the final diagnosis in $74.3 \% .^{72}$ 
Of the 7 cases with major differences between the FINE diagnosis and final CHD diagnosis (category $\mathrm{C}$ ), 43\% $(\mathrm{n}=3)$ were conotruncal abnormalities (Table 5). Prior studies have shown that conotruncal anomalies are the CHD in which discrepancies with the postnatal diagnosis are the most common. ${ }^{89-92}$

\section{Clinical implications of the study}

Based upon the study herein, there are several clinical implications regarding the FINE method: 1) it may be used to assess fetuses with normal hearts and a broad spectrum of CHD with a high sensitivity and specificity; 2) it can be considered both a cardiac screening and diagnostic tool in the clinical setting; 3) since STIC volume datasets, diagnostic planes, and VIS-Assistance videoclips can be transmitted by telemedicine for expert consultation, this expands the outreach of fetal cardiac imaging, which could favorably impact the current sensitivity of CHD; and 4) it can be used for educational and training purposes.

\section{Limitations}

In cases of CHD, only a single STIC volume per fetus was examined using FINE. It is possible that by examining multiple STIC volume datasets at a given gestational age, or examining STIC volumes over time, this would have led to improved and/or different diagnostic information (e.g. some CHD are progressive). The FINE method is not meant to replace real-time fetal echocardiography, since the latter allows evaluation of cardiac rate or rhythm disturbances, the performance of pulsed wave Doppler velocimetry, etc. Therefore, when fetal CHD is suspected, such patients should then undergo real-time sonographic examination by an appropriate sonologist (e.g. pediatric cardiologist). Finally, 
studies are required to determine the learning curve for FINE among operators with varying levels of experience.

\section{Conclusions}

We present herein for the first time the sensitivity and specificity of the FINE method in fetuses with normal hearts and CHD in the second to third trimesters. Since FINE identifies a broad spectrum of CHD with $98 \%$ sensitivity, this method could be used (1) prenatally to screen for and diagnose CHD.
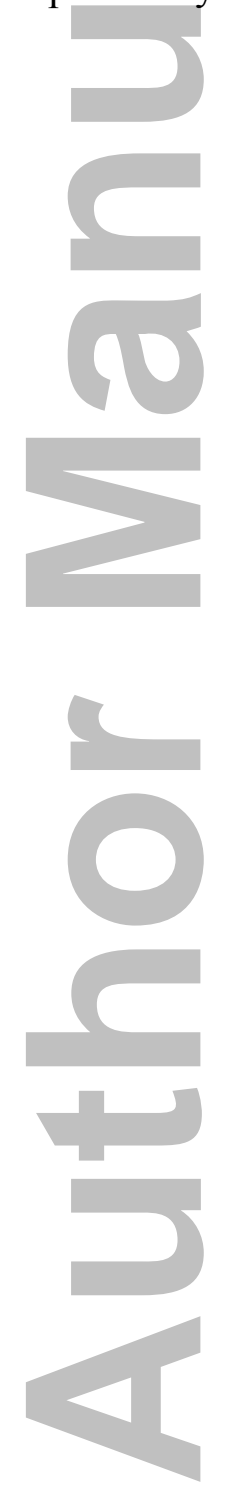


\section{$\underline{\text { ACKNOWLEDGMENTS }}$}

An application for a patent (“Apparatus and Method for Fetal Intelligent

Navigation Echocardiography") has been filed with the U.S. Patent and Trademark Office, and the patent is pending. Dr. Lami Yeo and Dr. Roberto Romero are co-inventors, along with Mr. Gustavo Abella and Mr. Ricardo Gayoso. The rights of Dr. Yeo and Dr. Romero have been assigned to Wayne State University, and NICHD/NIH, respectively.

The work of Dr. Romero was supported by the Perinatology Research Branch, Division of Intramural Research, Eunice Kennedy Shriver National Institute of Child Health and Human Development, NIH, DHHS. Dr. Romero has contributed to this work as part of his official duties as an employee of the United States Federal Government. Drs.

Lami Yeo and Suchaya Luewan were funded by Wayne State University through a service contract in support of the Perinatology Research Branch.

This research was supported, in part, by the Perinatology Research Branch, Division of Intramural Research, Eunice Kennedy Shriver National Institute of Child Health and Human Development, National Institutes of Health, Department of Health and Human Services (NICHD/NIH); and, in part, with Federal funds from NICHD, NIH under Contract No. HHSN275201300006C. 


\section{REFERENCES}

1. Simeone RM, Feldkamp ML, Reefhuis J, et al. CDC Grand Rounds: Understanding the Causes of Major Birth Defects - Steps to Prevention. MMWR Morb Mortal Wkly Rep 2015; 64:1104-1107.

2. Yang Q, Chen H, Correa A, Devine O, Mathews TJ, Honein MA. Racial differences in infant mortality attributable to birth defects in the United States, 1989-2002. Birth Defects Res A Clin Mol Teratol 2006; 76:706-713.

3. Allan L. Antenatal diagnosis of heart disease. Heart 2000; 83:367.

4. Friedberg MK, Silverman NH, Moon-Grady AJ, et al. Prenatal detection of congenital heart disease. J Pediatr 2009; 155:26-31.

5. Jaeggi ET, Sholler GF, Jones OD, Cooper SG. Comparative analysis of pattern, management and outcome of pre- versus postnatally diagnosed major congenital heart disease: a population-based study. Ultrasound Obstet Gynecol 2001; 17:380385.

6. Acherman RJ, Evans WN, Luna CF, et al. Prenatal detection of congenital heart disease in southern Nevada: the need for universal fetal cardiac evaluation. $J$ Ultrasound Med 2007; 26:1715-1719.

7. Garne E, Stoll C, Clementi M. Evaluation of prenatal diagnosis of congenital heart diseases by ultrasound: experience from 20 European registries. Ultrasound Obstet Gynecol 2001; 17:386-391.

8. Westin M, Saltvedt S, Bergman G, et al. Routine ultrasound examination at 12 or 18 gestational weeks for prenatal detection of major congenital heart 
malformations? A randomized controlled trial comprising 36,299 fetuses. BJOG 2006; 113:675-682.

9. Nikkila A, Bjorkhem G, Kallen B. Prenatal diagnosis of congenital heart defects a population based study. Acta Paediatr 2007; 96:49-52.

10. Pinto NM, Keenan HT, Minich LL, Puchalski MD, Heywood M, Botto LD. Barriers to prenatal detection of congenital heart disease: a population based study. Ultrasound Obstet Gynecol 2012; 40:418-425.

11. McBrien A, Sands A, Craig B, Dornan J, Casey F. Major congenital heart disease: antenatal detection, patient characteristics and outcomes. J Matern Fetal Neonatal Med 2009; 22:101-105.

12. Sklansky MS, Berman DP, Pruetz JD, Chang RK. Prenatal screening for major congenital heart disease: superiority of outflow tracts over the 4-chamber view. $J$ Ultrasound Med 2009; 28:889-899.

13. Allan L, Benacerraf B, Copel JA, et al. Isolated major congenital heart disease. Ultrasound Obstet Gynecol 2001; 17:370-379.

14. Carvalho JS, Mavrides E, Shinebourne EA, Campbell S, Thilaganathan B. Improving the effectiveness of routine prenatal screening for major congenital heart defects. Heart 2002; 88:387-391.

15. Hunter S, Heads A, Wyllie J, Robson S. Prenatal diagnosis of congenital heart disease in the northern region of England: benefits of a training programme for obstetric ultrasonographers. Heart 2000; 84:294-298. 
16. Rustico MA, Benettoni A, D'Ottavio G, et al. Early screening for fetal cardiac anomalies by transvaginal echocardiography in an unselected population: the role of operator experience. Ultrasound Obstet Gynecol 2000; 16:614-619.

17. Tegnander E, Eik-Nes SH. The examiner's ultrasound experience has a significant impact on the detection rate of congenital heart defects at the second-trimester fetal examination. Ultrasound Obstet Gynecol 2006; 28:8-14.

18. Wong SF, Chan FY, Cincotta RB, Lee-Tannock A, Ward C. Factors influencing the prenatal detection of structural congenital heart diseases. Ultrasound Obstet Gynecol 2003; 21:19-25.

19. Franklin O, Burch M, Manning N, Sleeman K, Gould S, Archer N. Prenatal diagnosis of coarctation of the aorta improves survival and reduces morbidity. Heart 2002; 87:67-69.

20. Acherman RJ, Evans WN, Luna CF, et al. Prenatal detection of congenital heart disease in southern Nevada: the need for universal fetal cardiac evaluation. $J$ Ultrasound Med 2007; 26:1715-1719.

21. Tibballs J, Cantwell-Barti A. Outcomes of management decisions by parents for their infants with hypoplastic left heart syndrome born with and without a prenatal diagnosis. J Paediatr Child Health 2008; 44:321-324.

22. Daubeney PE, Sharland GK, Cook AC, Keeton BR, Anderson RH, Webber SA. Pulmonary atresia with intact ventricular septum: impact of fetal echocardiography on incidence at birth and postnatal outcome. UK and Eire Collaborative Study of Pulmonary Atresia with Intact Ventricular Septum. Circulation 1998; 98:562-566. 
23. Tworetzky W, McElhinney DB, Reddy VM, Brook MM, Hanley FL, Silverman NH. Improved surgical outcome after fetal diagnosis of hypoplastic left heart syndrome. Circulation 2001; 103:1269-1273.

24. Kumar RK, Newburger JW, Gauvreau K, Kamenir SA, Hornberger LK. Comparison of outcome when hypoplastic left heart syndrome and transposition of the great arteries are diagnosed prenatally versus when diagnosis of these two conditions is made only postnatally. Am J Cardiol 1999; 83:1649-1653.

25. Verheijen PM, Lisowski LA, Stoutenbeek P, Hitchcock JF, Bennink GK, Meijboom EJ. Lactacidosis in the neonate is minimized by prenatal detection of congenital heart disease. Ultrasound Obstet Gynecol 2002; 19:552-555.

26. Schultz AH, Localio AR, Clark BJ, Ravishankar C, Videon N, Kimmel SE. Epidemiologic features of the presentation of critical congenital heart disease: implications for screening. Pediatrics 2008; 121:751-757.

27. Brown KL, Ridout DA, Hoskote A, Verhulst L, Ricci M, Bull C. Delayed diagnosis of congenital heart disease worsens preoperative condition and outcome of surgery in neonates. Heart 2006; 92:1298-1302.

28. van Velzen CL, Haak MC, Reijnders G, et al. Prenatal detection of transposition of the great arteries reduces mortality and morbidity. Ultrasound Obstet Gynecol $2015 ; 45: 320-325$.

29. Holland BJ, Myers JA, Woods CR Jr. Prenatal diagnosis of critical congenital heart disease reduces risk of death from cardiovascular compromise prior to planned 
neonatal cardiac surgery: a meta-analysis. Ultrasound Obstet Gynecol 2015; 45:631-638.

30. Grinenco S, Meller C, Marantz P, Izbizky G. Prenatal diagnosis of congenital heart disease: improving survival. Ultrasound Obstet Gynecol 2015; 46:633.

31. Bonnet D, Coltri A, Butera G, et al. Detection of transposition of the great arteries in fetuses reduces neonatal morbidity and mortality. Circulation 1999; 99:916-918.

32. Khoshnood B, De Vigan C, Vodovar V, et al. Trends in prenatal diagnosis, pregnancy termination, and perinatal mortality of newborns with congenital heart disease in France, 1983-2000: a population-based evaluation. Pediatrics 2005; 115:95-101.

33. Kipps AK, Feuille C, Azakie A, et al. Prenatal diagnosis of hypoplastic left heart syndrome in current era. Am J Cardiol 2011; 108:421-427.

34. Mahle WT, Clancy RR, McGaurn SP, Goin JE, Clark BJ. Impact of prenatal diagnosis on survival and early neurologic morbidity in neonates with the hypoplastic left heart syndrome. Pediatrics 2001; 107:1277-1282.

35. DeVore GR, Falkensammer P, Sklansky MS, Platt LD. Spatiotemporal image correlation (STIC): new technology for evaluation of the fetal heart. Ultrasound Obstet Gynecol 2003; 22:380-387.

36. Goncalves LF, Lee W, Chaiworapongsa T, et al. Four-dimensional ultrasonography of the fetal heart with spatiotemporal image correlation. Am J Obstet Gynecol 2003;

189:1792-1802. 
37. Chaoui R, Hoffmann J, Heling KS. Three-dimensional (3D) and 4D color Doppler fetal echocardiography using spatio-temporal image correlation (STIC). Ultrasound Obstet Gynecol 2004; 23:535-545.

38. Molina FS, Faro C, Sotiriadis A, Dagklis T, Nicolaides KH. Heart stroke volume and cardiac output by four-dimensional ultrasound in normal fetuses. Ultrasound Obstet Gynecol 2008; 32:181-187.

39. Tutschek B, Sahn DJ. Semi-automatic segmentation of fetal cardiac cavities: progress towards an automated fetal echocardiogram. Ultrasound Obstet Gynecol 2008; 32:176-180.

40. Zhao L, Wu Y, Chen S, et al. Feasibility study on prenatal cardiac screening using four-dimensional ultrasound with spatiotemporal image correlation: a multicenter study. PLoS One 2016; 11:e157477.

41. Avnet H, Mazaaki E, Shen O, Cohen S, Yagel S. Evaluating spatiotemporal image correlation technology as a tool for training nonexpert sonographers to perform examinations of the fetal heart. J Ultrasound Med 2016; 35:111-119.

42. Bennasar M, Martínez JM, Olivella A, et al. Feasibility and accuracy of fetal echocardiography using four-dimensional spatiotemporal image correlation technology before 16 weeks' gestation. Ultrasound Obstet Gynecol 2009; 33:645651.

43. Yeo L, Romero R. How to acquire cardiac volumes for sonographic examination of the fetal heart: Part 1. J Ultrasound Med 2016; 35: 1021-1042. 
44. Novaes JY, Zamith MM, Araujo Junior E, Barreto EQ, Barros FS, Moron AF. Screening of congenital heart diseases by three-dimensional ultrasound using spatiotemporal image correlation: influence of professional experience. Echocardiography 2016; 33: 99-104.

45. Jantarasaengaram S, Vairojanavong K: Eleven fetal echocardiographic planes using 4-dimensional ultrasound with spatio-temporal image correlation (STIC): a logical approach to fetal heart volume analysis. Cardiovasc Ultrasound 2010; 8:41.

46. Crispi F, Gratacós E. Fetal cardiac function: technical considerations and potential research and clinical applications. Fetal Diagn Ther 2012; 32:47-64.

47. Cohen L, Mangers K, Grobman WA, Platt LD. Satisfactory visualization rates of standard cardiac views at 18 to 22 weeks' gestation using spatiotemporal image correlation. J Ultrasound Med 2009; 28:1645-1650.

48. Luewan S, Yanase Y, Tongprasert F, Srisupundit K, Tongsong T. Fetal cardiac dimensions at 14-40 weeks' gestation obtained using cardio-STIC-M. Ultrasound Obstet Gynecol 2011; 37:416-422.

49. Uittenbogaard LB, Haak MC, Spreeuwenberg MD, van Vugt JM. Fetal cardiac function assessed with four-dimensional ultrasound imaging using spatiotemporal image correlation. Ultrasound Obstet Gynecol 2009; 33:272-281.

50. Yeo L, Romero R, Jodicke C, et al. Simple targeted arterial rendering (STAR) technique: a novel and simple method to visualize the fetal cardiac outflow tracts. Ultrasound Obstet Gynecol 2011; 37:549-556. 
51. Espinoza J, Kusanovic JP, Goncalves LF, et al. A novel algorithm for comprehensive fetal echocardiography using 4-dimensional ultrasonography and tomographic imaging. J Ultrasound Med 2006; 25:947-956.

52. Araujo Junior E, Rolo LC, Rocha LA, Nardozza LM, Moron AF. The value of 3D and 4D assessments of the fetal heart. Int $J$ Womens Health 2014; 6:501-507.

53. Goncalves LF, Romero R, Espinoza J, et al. Four-dimensional ultrasonography of the fetal heart using color Doppler spatiotemporal image correlation. $J$ Ultrasound Med 2004; 23:473-481.

54. Turan S, Turan OM, Ty-Torredes K, Harman CR, Baschat AA. Standardization of the first-trimester fetal cardiac examination using spatiotemporal image correlation with tomographic ultrasound and color Doppler imaging. Ultrasound Obstet Gynecol 2009; 33:652-656.

55. Yeo L, Romero R. How to acquire cardiac volumes for sonographic examination of the fetal heart: Part 2. J Ultrasound Med 2016; 35:1043-1066.

56. Yagel S, Cohen SM, Shapiro I, Valsky DV. 3D and 4D ultrasound in fetal cardiac scanning: a new look at the fetal heart. Ultrasound Obstet Gynecol 2007; 29:8195.

57. Rizzo G, Capponi A, Muscatello A, Cavicchioni O, Vendola M, Arduini D. Examination of the fetal heart by four-dimensional ultrasound with spatiotemporal image correlation during routine second-trimester examination: the 'three-steps technique'. Fetal Diagn Ther 2008; 24:126-131. 
58. Hamill N, Yeo L, Romero R, et al. Fetal cardiac ventricular volume, cardiac output, and ejection fraction determined with 4-dimensional ultrasound using spatiotemporal image correlation and virtual organ computer-aided analysis. Am $J$ Obstet Gynecol 2011; 205:76.e1-10.

59. Barros FS, Moron AF, Rolo LC, et al. Fetal myocardial wall area: constructing a reference range by means of spatiotemporal image correlation in the rendering mode. Fetal Diagn Ther 2015; 37:44-50.

60. DeVore GR, Polanco B, Sklansky MS, Platt LD. The 'spin' technique: a new method for examination of the fetal outflow tracts using three-dimensional ultrasound. Ultrasound Obstet Gynecol 2004; 24:72-82.

61. Yeo L, Romero R, Jodicke C, et al. Four-chamber view and 'swing technique' (FAST) echo: a novel and simple algorithm to visualize standard fetal echocardiographic planes. Ultrasound Obstet Gynecol 2011; 37:423-431.

62. Nardozza LM, Rolo LC, Araujo Júnior E, et al. Reference range for fetal interventricular septum area by means of four-dimensional ultrasonography using spatiotemporal image correlation. Fetal Diagn Ther 2013; 33:110-115.

63. Viñals F. Current experience and prospect of internet consultation in fetal cardiac ultrasound. Fetal Diagn Ther 2011; 30:83-87.

64. Godfrey ME, Messing B, Valsky DV, Cohen SM, Yagel S. Fetal cardiac function: M-mode and 4D spatiotemporal image correlation. Fetal Diagn Ther 2012; 32:1721. 
65. Abuhamad A, Chaoui R. Three-dimensional fetal echocardiography: basic and advanced applications. In: Abuhamad A, Chaoui R (eds). A Practical Guide to Fetal Echocardiography: Normal and Abnormal Hearts. Philadelphia, PA: Lippincott Williams \& Wilkins; 2010: 110-127.

66. Yeo L, Romero R. Color and power Doppler combined with fetal intelligent navigation echocardiography (FINE) to evaluate the fetal heart. Ultrasound Obstet Gynecol 2017; 50:476-491.

67. Adriaanse BM, van Vugt JM, Haak MC. Three- and four-dimensional ultrasound in fetal echocardiography: an up-to-date overview. J Perinatol 2016; 36: 685-693.

68. Espinoza J. Contemporary clinical applications of spatio-temporal image correlation in prenatal diagnosis. Curr Opin Obstet Gynecol 2011; 23:94-102.

69. Goncalves LF, Espinoza J, Romero R, et al. A systematic approach to prenatal diagnosis of transposition of the great arteries using 4-dimensional ultrasonography with spatiotemporal image correlation. J Ultrasound Med 2004; 23:1225-1231.

70. Paladini D, Sglavo G, Greco E, Nappi C. Cardiac screening by STIC: can sonologists performing the 20 -week anomaly scan pick up outflow tract abnormalities by scrolling the A-plane of STIC volumes? Ultrasound Obstet Gynecol 2008; 32:865-870.

71. Gindes L, Hegesh J, Weisz B, Gilboa Y, Achiron R. Three and four dimensional ultrasound: a novel method for evaluating fetal cardiac anomalies. Prenat Diagn 2009; 29:645-653. 
72. Bennasar M, Martínez JM, Gómez O, et al. Accuracy of four-dimensional spatiotemporal image correlation echocardiography in the prenatal diagnosis of congenital heart defects. Ultrasound Obstet Gynecol 2010; 36:458-464.

73. Espinoza J, Lee W, Comstock C, et al. Collaborative study on 4-dimensional echocardiography for the diagnosis of fetal heart defects: the COFEHD study. $J$ Ultrasound Med 2010; 29:1573-1580.

74. Adriaanse BM, Tromp CH, Simpson JM, et al. Interobserver agreement in detailed prenatal diagnosis of congenital heart disease by telemedicine using fourdimensional ultrasound with spatiotemporal image correlation. Ultrasound Obstet Gynecol 2012; 39:203-209.

75. Gómez O, Soveral I, Bennasar M, et al. Accuracy of fetal echocardiography in the differential diagnosis between truncus arteriosus and pulmonary atresia with ventricular septal defect. Fetal Diagn Ther 2016; 39:90-99.

76. Yeo L, Romero R. Intelligent navigation to improve obstetrical sonography. Ultrasound Obstet Gynecol 2016; 47: 403-409.

77. Yeo L, Romero R. Fetal Intelligent Navigation Echocardiography (FINE): a novel method for rapid, simple, and automatic examination of the fetal heart. Ultrasound Obstet Gynecol 2013; 42:268-284.

78. Garcia M, Yeo L, Romero R, et al. Prospective evaluation of the fetal heart using Fetal Intelligent Navigation Echocardiography (FINE). Ultrasound Obstet Gynecol $2016 ; 47: 450-459$. 
79. Veronese P, Bogana G, Cerutti A, Yeo L, Romero R, Gervasi MT. A prospective study of the use of fetal intelligent navigation echocardiography (FINE) to obtain standard fetal echocardiography views. Fetal Diagn Ther 2017; 41:89-99.

80. Yeo L, Luewan S, Markush D, Gill N, Romero R. Prenatal diagnosis of dextrocardia with complex congenital heart disease using fetal intelligent navigation echocardiography (FINE) and a literature review [published online ahead of print June 23, 2017]. Fetal Diagn Ther. doi: 10.1159/000468929.

81. Evans MI, Galen RS, Britt DW. Principles of screening. Semin Perinatol 2005; 29:364-366.

82. Allan LD, Sharland GK, Milburn A, et al. Prospective diagnosis of 1,006 consecutive cases of congenital heart disease in the fetus. J Am Coll Cardiol 1994; $23: 1452-1458$.

83. Angiulli A, Tai A, Easterbrook S. Voluson: Electronic 4D imaging - Designed for Women's Health. GE Healthcare; September 2014.

84. Guasina F, Bellussi F, Morganelli G, Salsi G, Pilu G, Simonazzi G. Electronic STIC improves four-dimensional fetal echocardiography [published online ahead of print March 24, 2017]. Ultrasound Obstet Gynecol. doi:10.1002/uog.17474.

85. Deeks JJ, Altman DG. Diagnostic tests 4: likelihood ratios. BMJ 2004; 329:168169.

86. Jaeschke R, Guyatt G, Lijmer J. Diagnostic tests. In: Guyatt G, Rennie D (eds). Users' Guides to the Medical Literature. Chicago, IL: AMA Press; 2002:121-140. 
87. Gonçalves LF, Espinoza J, Romero R, et al. Four-dimensional ultrasonography of the fetal heart using a novel Tomographic Ultrasound Imaging display. $J$ Perinat Med 2006; 34:39-55.

88. Aguilera M, Dummer K. Concordance of fetal echocardiography in the diagnosis of congenital cardiac disease utilizing updated guidelines [published online ahead of print March 12, 2017]. $J$ Matern Fetal Neonatal Med. doi: 10.1080/14767058.2017.1297791.

89. Galindo A, Mendoza A, Arbues J, Grañeras A, Escribano D, Nieto O. Conotruncal anomalies in fetal life: accuracy of diagnosis, associated defects and outcome. Eur J Obstet Gynecol Reprod Biol 2009; 146:55-60.

90. Paladini D, Rustico M, Todros T, et al. Conotruncal anomalies in prenatal life. Ultrasound Obstet Gynecol 1996; 8:241-246.

91. Tometzki AJP, Suda K, Khol T, Kovalchin JP, Silverman NH. Accuracy of prenatal echocardiographic diagnosis and prognosis of fetuses with conotruncal anomalies. J Am Coll Cardiol 1999; 33:1696-1701.

92. Sivanandam S, Glickstein JS, Printz BF, et al. Prenatal diagnosis of conotruncal malformations: diagnostic accuracy, outcome, chromosomal abnormalities and extracardiac anomalies. Am J Perinatol 2006; 23:241-245.

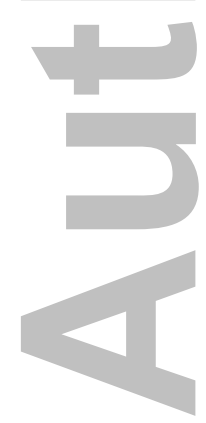


Table 1. Features of Fetal Intelligent Navigation Echocardiography (FINE) method

Intelligent navigation technology

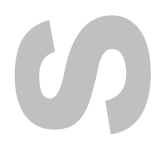

\section{STICLoop ${ }^{\mathrm{TM}}$}
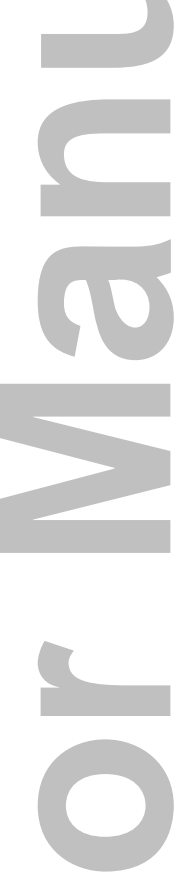

Anatomic Box ${ }^{\circledR}$

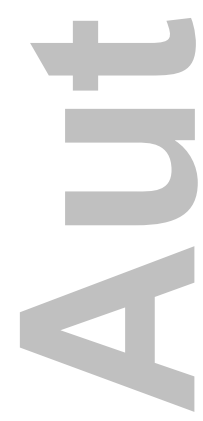

New method of interrogation of a volume dataset whereby identification and selection of key anatomical landmarks allows the system to: 1) generate a geometrical reconstruction of the organ of interest (e.g. fetal heart); and 2) automatically navigate, find, extract, and display specific diagnostic planes

Two-dimensional cine loop tool developed to aid the user in determining the appropriateness of STIC volume datasets before applying the FINE method to such volumes

\section{STICLoop criteria:}

1) Fetal spine located between the 5- and 7-o'clock positions (reducing the possibility of shadowing from the ribs or spine)

2) Minimal or absent shadowing (including the three vessels and trachea view) which could obscure visualization of cardiac anatomy

3) Adequate image quality

4) Upper mediastinum and stomach included within the volume and clearly visible

5) Minimal or no motion artifacts observed in the STICLoop (i.e. smooth sweep without evidence of abrupt jumps or discontinuous movements)

6) Chest circumference contained with the region of interest

7) Sequential axial planes parallel to each other, similar to a sliced loaf of bread (i.e. no 'drifting spine' from the four-chamber view down to the stomach)

8) No azimuthal issues observed (i.e. atria/ventricles do not appear foreshortened in the four-chamber view)

9) Minimal or no motion artifacts observed in the sagittal plane

Tool used to mark seven anatomical structures of the fetal heart within the STIC volume to generate a geometrical model of the fetal heart:

1) Cross-section of the aorta at the level of the stomach

2) Cross-section of the aorta at the level of the four-chamber view

3) Crux

4) Right atrial wall

5) Pulmonary valve

6) Cross-section of the superior vena cava

7) Transverse aortic arch 


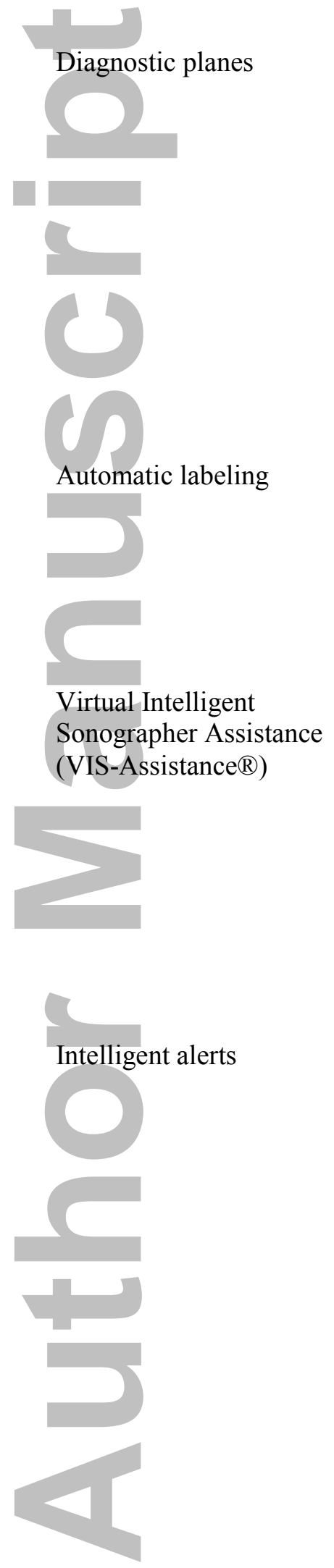

Nine standard fetal echocardiography views automatically displayed by FINE in a single template:

1) Four chamber

2) Five chamber

3) Left ventricular outflow tract

4) Short-axis view of great vessels/right ventricular outflow tract

5) Three vessels and trachea

6) Abdomen/stomach

7) Ductal arch

8) Aortic arch

9) Superior and inferior vena cava

- Fetal echocardiography views, anatomical structures (atrial and ventricular chambers, great vessels, venae cavae and stomach), left and right side of fetus, and cranial and caudal ends

- Labeling stays with the corresponding anatomical structure(s), even as the image is increased or decreased in size

Operator-independent sonographic navigation and exploration of surrounding structures in a cardiac diagnostic plane of interest ('virtual' sonographer)

- Double VIS-Assistance: technique in which VIS-Assistance is applied twice to a diagnostic plane of interest, allowing expanded navigational movements and further exploration

- Triple VIS-Assistance: technique in which VIS-Assistance is applied three times to a diagnostic plane of interest, allowing expanded navigational movements and further exploration

- Captions and/or a movie notifying the user about potential issues with the STIC volume dataset. The movies depict reference examples to guide and teach the operator.

- If intelligent alerts appear, this will occur during the marking process

- Three types: 1) Breech alert: notifies user that the fetus appears to be in a breech presentation; 2) Possible drifting spine alert: notifies user that there may be a 'drifting' fetal spine in the volume dataset (i.e. when the spine location migrates on the screen); and 3) Spine location alert: notifies user that the fetal spine appears to be located at a position different from what is recommended (i.e. between 5- and 7- o'clock). Once a spine location alert has appeared, three Marking alerts will appear next in sequence.

- A spine location alert will only appear if the fetal spine is located at these "times" (o'clock): 12, 1, 2, 3, 4, between 4 and 5 , between 7 and $8,8,9,10,11$ 


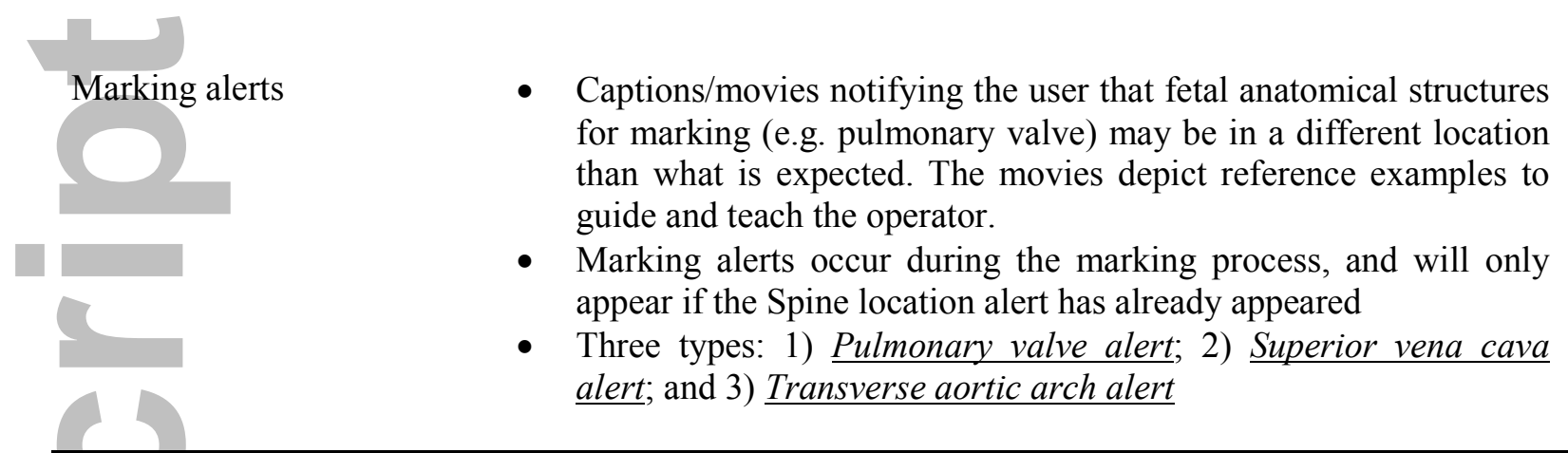

STIC, spatiotemporal image correlation
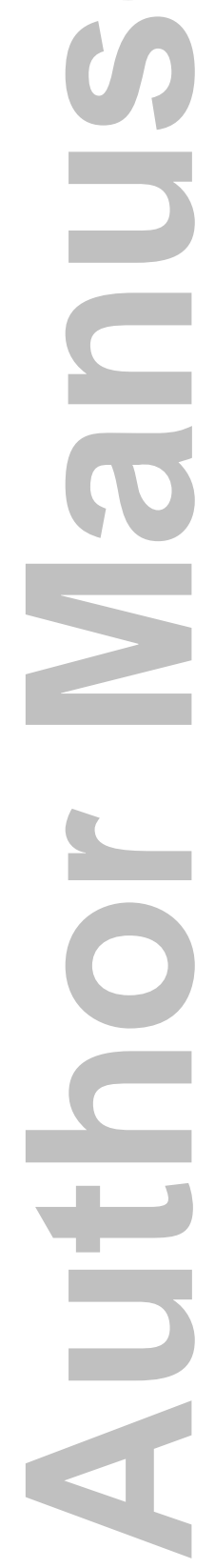
Table 2. Fetal Intelligent Navigation Echocardiography (FINE): success rates of obtaining nine fetal echocardiography views after applying intelligent navigation to 100 normal spatiotemporal image correlation (STIC) volume datasets using diagnostic planes and/or Virtual Intelligent Sonographer Assistance (VIS-Assistance)

\begin{tabular}{|c|c|c|c|c|c|c|}
\hline \multirow[b]{2}{*}{$\begin{array}{l}\text { Fetal } \\
\text { echocardiography } \\
\text { view }\end{array}$} & \multicolumn{2}{|c|}{$\begin{array}{l}\text { Diagnostic plane } \\
\qquad(n=100)\end{array}$} & \multicolumn{2}{|c|}{$\begin{array}{l}\text { VIS-Assistance } \\
\qquad(\mathrm{n}=100)\end{array}$} & \multicolumn{2}{|c|}{$\begin{array}{l}\text { Diagnostic plane } \\
\text { and/or } \\
\text { VIS-Assistance } \\
\quad(n=100)\end{array}$} \\
\hline & $\mathrm{n}(\%)$ & $95 \% \mathrm{CI}^{*}$ & n $(\%)$ & $95 \% \mathrm{CI}^{*}$ & $\mathrm{n}(\%)$ & $95 \% \mathrm{CI}^{*}$ \\
\hline 1. Four-chamber & $97(97)$ & 91 to 99 & $100(100)$ & 96 to 100 & $100(100)$ & 96 to 100 \\
\hline 2. Five-chamber & $99(99)$ & 94 to $>99.9$ & $100(100)$ & 96 to 100 & $100(100)$ & 96 to 100 \\
\hline 3. LVOT & 99 (99) & 94 to $>99.9$ & $100(100)$ & 96 to 100 & $100(100)$ & 96 to 100 \\
\hline $\begin{array}{l}\text { 4. Short axis view of } \\
\text { great vessels/RVOT }\end{array}$ & 97 (97) & 91 to 99 & $100(100)$ & 96 to 100 & $100(100)$ & 96 to 100 \\
\hline 5. $3 \mathrm{VT}$ & $99(99)$ & 94 to $>99.9$ & $100(100)$ & 96 to 100 & $100(100)$ & 96 to 100 \\
\hline 6. Abdomen/Stomach & $100(100) \dagger$ & 96 to 100 & $100(100) \ddagger$ & 96 to 100 & $100(100)$ & 96 to 100 \\
\hline 7. Ductal arch & $95(95)$ & 95 to 100 & $100(100)$ & 96 to 100 & $100(100)$ & 96 to 100 \\
\hline 8. Aortic arch & $98(98)$ & 95 to 100 & $100(100)$ & 96 to 100 & $100(100)$ & 96 to 100 \\
\hline 9. SVC/IVC & $94(94)$ & 95 to 100 & $100(100)$ & 96 to 100 & $100(100)$ & 96 to 100 \\
\hline - $\mathrm{SVC}$ & $97(97)$ & 91 to 99 & -- & -- & -- & -- \\
\hline - IVC & $97(97)$ & 91 to 99 & -- & -- & -- & -- \\
\hline
\end{tabular}

*The Wald method was used to calculate two-sided CIs for proportions expressed in the table; as the true proportion cannot exceed 100\%, upper confidence limits are truncated at $100 \%$.

$\uparrow$ Defined as visualization of the stomach in the diagnostic plane 
:Defined as visualization of both the stomach and four-chamber view in VIS-Assistance ${ }^{\circledR}$ (to determine situs)

$3 \mathrm{VT}$, three vessels and trachea; IVC, inferior vena cava; LVOT, left ventricular outflow tract; RVOT, right ventricular outflow tract; SVC, superior vena cava.
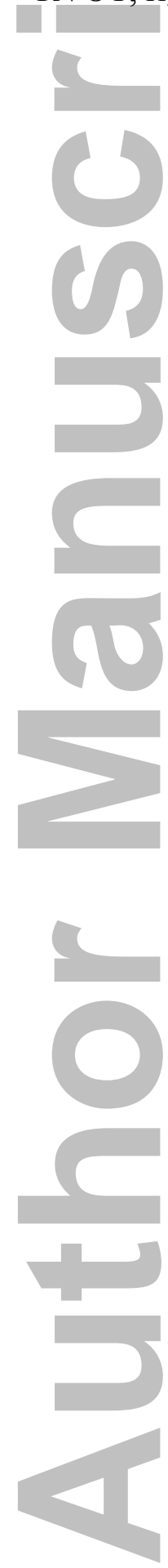
Table 3. Main categories of congenital heart defects evaluated by the FINE method

Congenital heart defect

$\mathrm{n}(\%)$

Conotruncal anomalies

$21(42)$

Tetralogy of Fallot*

$9(18)$

DORV

Complete TGV

Pulmonary atresia with VSD

$2(4)$

Truncus arteriosus

Left heart anomalies

$10(20)$

Coarctation of aorta

Hypoplastic left heart

Interrupted aortic arch

Right heart anomalies

Pulmonary atresia with intact ventricular septum

Tricuspid atresia with VSD

Pulmonary stenosis

Ebstein anomaly

\section{Complex cardiac defects}

$6(12)$

Small RV, VSD, small pulmonary artery, large pericardial effusion

Hypoplastic left heart, DORV, TGV, stomach on fetal right side

Double inlet left ventricle, TGV, pulmonary stenosis, ASD, left SVC

$1(2)$

Double inlet right ventricle, DORV, coarctation of aorta

$1(2)$

Interrupted IVC with azygos vein continuation; stomach on right side

$1(2)$

LV non-compaction, dilated cardiomyopathy, left SVC, secundum ASD, VSD,

hypoplastic tricuspid valve

\section{Septal defects}

Atrioventricular septal defect

*Includes the following types ( $n=3): 1$ ) tetralogy of Fallot with right aortic arch; 2) tetralogy of Fallot with absent pulmonary valve; 3 ) tetralogy of Fallot with absent pulmonary valve, right aortic arch, vascular ring

ASD, atrial septal defect; DORV, double outlet right ventricle; IVC, inferior vena cava; LV, left ventricle; RV, right ventricle; SVC, superior vena cava; TGV, transposition of the great vessels; VSD, ventricular septal defect 
Table 4. Characteristics of FINE fundamental in determining whether the fetal heart is abnormal or not, and in determining the specific cardiac diagnosis

Characteristic

FINE

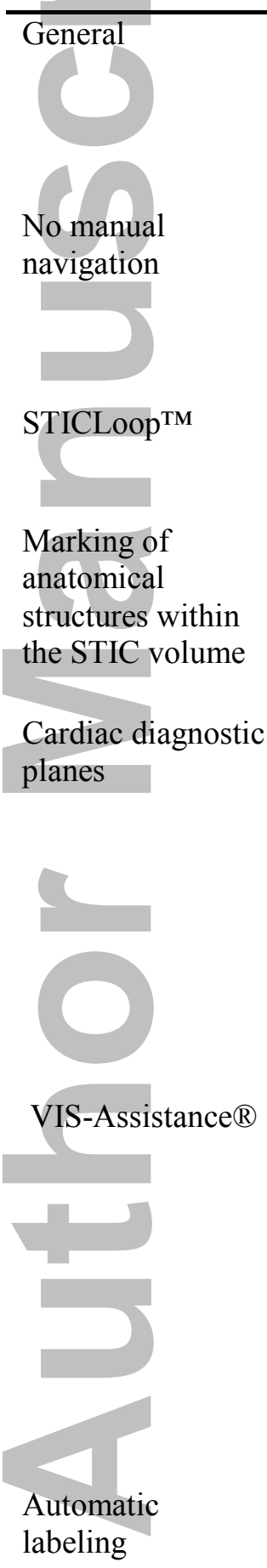

- Automatic realignment of STIC volume, and reorientation and standardization of the anatomical position so that the fetus and cardiac diagnostic planes are consistently displayed in the same manner each time

- Manual standardization or manipulation of the STIC volume dataset and reference planes is not required (e.g. alignment or rotation)

- Reduced operator dependency

- Examination of the fetal heart is standardized and simplified

- While the two-dimensional cine loop is automatically scrolling in a continuous fashion, abnormal cardiac anatomy is often displayed

- During the marking process, sometimes it is evident that: 1) anatomical structures are absent; 2) anatomical structures are not in their usual location; or 3) marking anatomical structures is difficult. One explanation is the presence of CHD.

- All nine planes (including transverse and sagittal) are displayed simultaneously in a single template

- Various features of the CHD can be visualized and compared side-byside (e.g. overriding aorta, ventricular septal defect, pulmonary stenosis in tetralogy of Fallot)

- Same specific abnormality can be confirmed in multiple echocardiography views at the same time (e.g. hypoplasia of the pulmonary artery seen in the $3 \mathrm{VT}$ view, short-axis view of great vessels/right ventricular outflow tract, and ductal arch view)

- Depiction of cardiac abnormalities when the diagnostic plane appears normal

- Provides further diagnostic information even when the diagnostic plane is abnormal

- Changes a suspected abnormal fetal echocardiography view to one that is interpreted as normal

- Improves the success of obtaining the fetal echocardiography view of interest when this is not initially obtained via the diagnostic plane

- Double, triple VIS-Assistance techniques

- Assists in identification of fetal echocardiography views, anatomical structures (atrial and ventricular chambers, great vessels, venae cavae and stomach), left and right side of fetus, and cranial and caudal ends 
Color Doppler

Depicts abnormal fetal cardiac anatomy and/or hemodynamic flow FINE characteristics

3VT, three vessels and trachea view; CHD, congenital heart defect; STIC, spatiotemporal image correlation; VIS-Assistance ${ }^{\circledR}$, Virtual Intelligent Sonographer Assistance
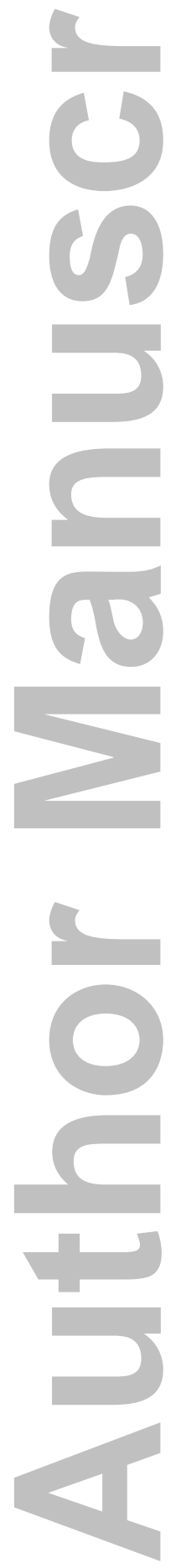
Table 5. Details of congenital heart defect cases with major discordancy between the FINE diagnosis compared to final diagnosis

GA (weeks)
FINE Diagnosis
Final Diagnosis
19 Complete atrioventricular septal defect, univentricle, large VSD, pulmonary stenosis, DORV, TGV, stomach on fetal right side

21 Tetralogy of Fallot

22 Left ventricle smaller than right ventricle, dilated left atrium, mitral dysplasia, aortic stenosis, VSD, DORV, left SVC, small pulmonary artery

26 Normal

30 Tetralogy of Fallot

35 LV non-compaction, dilated cardiomyopathy, left SVC, VSD, aortic stenosis, small pulmonary artery and ductus arteriosus, hypoplastic and dysplastic tricuspid valve

37 Tetralogy of Fallot
Hypoplastic left heart, DORV, $\mathrm{TGV}$, stomach on fetal right side

Pulmonary atresia, VSD

Variant of hypoplastic left heart, mitral dysplasia, aortic atresia, VSD

Pulmonary artery branch stenosis, small secundum ASD

Pulmonary atresia, VSD, supravalvular aortic stenosis

LV non-compaction, dilated cardiomyopathy, left SVC, VSD, secundum ASD, hypoplastic tricuspid valve

DORV, VSD, pulmonary stenosis, left SVC

$\overline{\mathrm{ASD}}$, atrial septal defect; DORV, double outlet right ventricle; GA, gestational age; LV, left ventricle; SVC, superior vena cava; TGV, transposition of great vessels; VSD, ventricular septal defect 


\section{$\underline{\text { Video Legends }}$}

Video 1: Nine normal cardiac diagnostic planes in a single template with the unique feature of automatic labeling (through intelligent navigation) of each plane, anatomical structures, fetal left and right sides, and cranial and caudal ends (also see Figure 1). The labeling is distinctive because it stays with the corresponding anatomical structure(s), even as the image is increased or decreased in size. A, transverse aortic arch; Ao, aorta; Desc., descending; IVC, inferior vena cava; $L A$, left atrium; $L V$, left ventricle; $P$, pulmonary artery; $P A$, pulmonary artery; $R A$, right atrium; $R V$, right ventricle; $R V O T$, right ventricular outflow tract; $S$, superior vena cava; SVC, superior vena cava; Trans., transverse

Video 2: Application of the FINE method to a fetus with tetralogy of Fallot at 23 weeks of gestation (diagnostic planes or VIS-Assistance with automatic labeling are shown) (also see Figure 2). Six echocardiography views were abnormal and demonstrate the typical features of this cardiac defect. The three vessels and trachea view shows a narrow pulmonary artery due to stenosis, while the transverse aortic arch is prominent. There is a 'Y-shaped' appearance of the great vessels. As is commonly noted in conotruncal abnormalities, the four-chamber view appeared normal in the diagnostic plane; however, VIS-Assistance demonstrates a large ventricular septal defect (not shown here). The five-chamber view shows a ventricular septal defect. The left ventricular outflow tract view shows an overriding aorta, dilated aortic root, and ventricular septal defect. In the short axis view of great vessels/right ventricular outflow tract (obtained via VIS-Assistance), the pulmonary artery is narrow with a tortuous ductus arteriosus. There is difficulty in visualizing a normal ductal arch. In the aortic arch view, the aortic root is dilated and there is a prominent ascending aorta. A, transverse aortic arch; Ao, aorta; Desc., descending; IVC, inferior vena cava; LA, left atrium; LV, left ventricle; $P$, pulmonary artery; $P A$, pulmonary artery; $R A$, right atrium; $R V$, right ventricle; $R V O T$, right ventricular outflow tract; $S$, superior vena cava; SVC, superior vena cava; Trans., transverse

Video 3: Application of the FINE method to a fetus with coarctation of the aorta at 24 weeks of gestation (diagnostic planes or VIS-Assistance with automatic labeling are shown) (also see Figure 3 ). Seven echocardiography views are abnormal. The three vessels and trachea view shows a narrow transverse aortic arch. In the four-chamber view, the left side of the heart is smaller than the right side; however, the left ventricle is apex-forming and there is good movement of the mitral valve. The right side of the heart appears enlarged, with the right ventricle being moderately dilated and hypertrophied. The five-chamber view shows similar findings to that of the four-chamber view. In addition, there is a narrow aortic root. The left ventricular outflow tract view shows a narrow aorta (obtained via VIS-Assistance). In the short-axis view of great vessels/right ventricular outflow tract, the cross-section of the aorta is small compared to the pulmonary artery. The enlarged right atrium is apparent. The ductal arch view demonstrates that the cross-section of the aorta is small compared to the pulmonary artery. In the aortic arch view, the coarctation is demonstrated as hypoplasia and narrowing of the transverse aortic arch as well as in the isthmus region. A, transverse aortic arch; Ao, aorta; Desc., descending; IVC, inferior vena cava; $L A$, left atrium; $L V$, left ventricle; $P$, pulmonary artery; $P A$, pulmonary artery; $R A$, right atrium; $R V$, right ventricle; $R V O T$, right ventricular outflow tract; $S$, superior vena cava; SVC, superior vena cava; Trans., transverse 
Video 4: VIS-Assistance of the left ventricular outflow tract view in a 19 week fetus with hypoplastic left heart, double outlet right ventricle, transposition of the great vessels, and fetal stomach on the right side (also see Figure 4). The abnormal diagnostic plane (left panel) demonstrates a single vessel arising from the right ventricle that is consistent with the pulmonary artery due to its bifurcation. A second vessel could not be clearly identified. However, when VIS-Assistance is activated (right panel), automatic navigational movements now demonstrate a second vessel (aorta) which is rightward and anterior, and exiting the right ventricle. These two vessels (indicated by white arrows) are parallel and side-by-side, consistent with transposition.
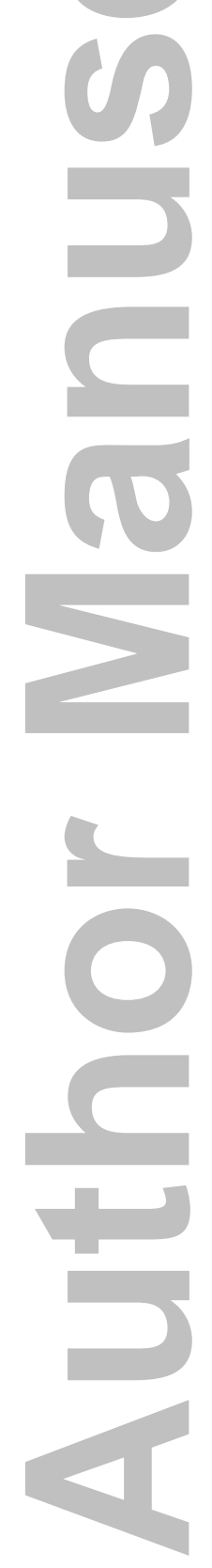


\section{Figure Legends}

Figure 1: Application of the Fetal Intelligent Navigation Echocardiography (FINE) method to a fetus with a normal fetal heart. Nine normal cardiac diagnostic planes in a single template are shown with the unique feature of automatic labeling (through intelligent navigation) of each plane, anatomical structures, fetal left and right sides, and cranial and caudal ends (also see Video 1). The labeling is distinctive because it stays with the corresponding anatomical structure(s), even as the image is increased or decreased in size. A, transverse aortic arch; Ao, aorta; Desc., descending; IVC, inferior vena cava; LA, left atrium; LV, left ventricle; $P$, pulmonary artery; $P A$, pulmonary artery; $R A$, right atrium; $R V$, right ventricle; $R V O T$, right ventricular outflow tract; $S$, superior vena cava; $S V C$, superior vena cava; Trans., transverse

Figure 2: Application of the FINE method to a fetus with tetralogy of Fallot at 23 weeks of gestation (diagnostic planes or VIS-Assistance with automatic labeling are shown) (also see Video 2). Six echocardiography views were abnormal and demonstrate the typical features of this cardiac defect. The three vessels and trachea view shows a narrow pulmonary artery due to stenosis, while the transverse aortic arch is prominent. There is a 'Y-shaped' appearance of the great vessels. As is commonly noted in conotruncal abnormalities, the four-chamber view appeared normal in the diagnostic plane; however, VIS-Assistance demonstrates a large ventricular septal defect (not shown here). The five-chamber view shows a ventricular septal defect. The left ventricular outflow tract view shows an overriding aorta, dilated aortic root, and ventricular septal defect. In the short axis view of great vessels/right ventricular outflow tract (obtained via VIS-Assistance), the pulmonary artery is narrow with a tortuous ductus arteriosus. There is difficulty in visualizing a normal ductal arch. In the aortic arch view, the aortic root is dilated and there is a prominent ascending aorta. A, transverse aortic arch; Ao, aorta; Desc., descending; IVC, inferior vena cava; LA, left atrium; LV, left ventricle; $P$, pulmonary artery; $P A$, pulmonary artery; $R A$, right atrium; $R V$, right ventricle; $R V O T$, right ventricular outflow tract; $S$, superior vena cava; SVC, superior vena cava; Trans., transverse

Figure 3: Application of the FINE method to a fetus with coarctation of the aorta at 24 weeks of gestation (diagnostic planes or VIS-Assistance with automatic labeling are shown) (also see Video 3). Seven echocardiography views are abnormal. The three vessels and trachea view shows a narrow transverse aortic arch. In the four-chamber view, the left side of the heart is smaller than the right side; however, the left ventricle is apex-forming. The right side of the heart appears enlarged, with the right ventricle being moderately dilated and hypertrophied. The five-chamber view shows similar findings to that of the four-chamber view. In addition, there is a narrow aortic root. The left ventricular outflow tract view shows a narrow aorta (obtained via VIS-Assistance). In the short-axis view of great vessels/right ventricular outflow tract, the cross-section of the aorta is small compared to the pulmonary artery. The enlarged right atrium is apparent. The ductal arch view demonstrates that the cross-section of the aorta is small compared to the pulmonary artery. In the aortic arch view, the coarctation is demonstrated as hypoplasia and narrowing of the transverse aortic arch as well as in the isthmus region. A, transverse aortic arch; Ao, aorta; Desc., descending; IVC, inferior vena cava; $L A$, left atrium; $L V$, left ventricle; $P$, pulmonary artery; $P A$, pulmonary artery; $R A$, right atrium; $R V$, right ventricle; $R V O T$, right ventricular outflow tract; $S$, superior vena cava; $S V C$, superior vena cava; Trans., transverse 
Figure 4: VIS-Assistance of the left ventricular outflow tract view in a 19 week fetus with hypoplastic left heart, double outlet right ventricle, transposition of the great vessels, and fetal stomach on the right side (also see Video 4). The abnormal diagnostic plane (left panel) demonstrates a single vessel arising from the right ventricle that is consistent with the pulmonary artery due to its bifurcation. A second vessel could not be clearly identified. However, when VIS-Assistance is activated (right panel), automatic navigational movements now demonstrate a second vessel (aorta) which is rightward and anterior, and exiting the right ventricle. These two vessels are parallel and side-by-side, consistent with transposition. $A O$, aorta; $P A$, pulmonary artery; $R V$, right ventricle. 


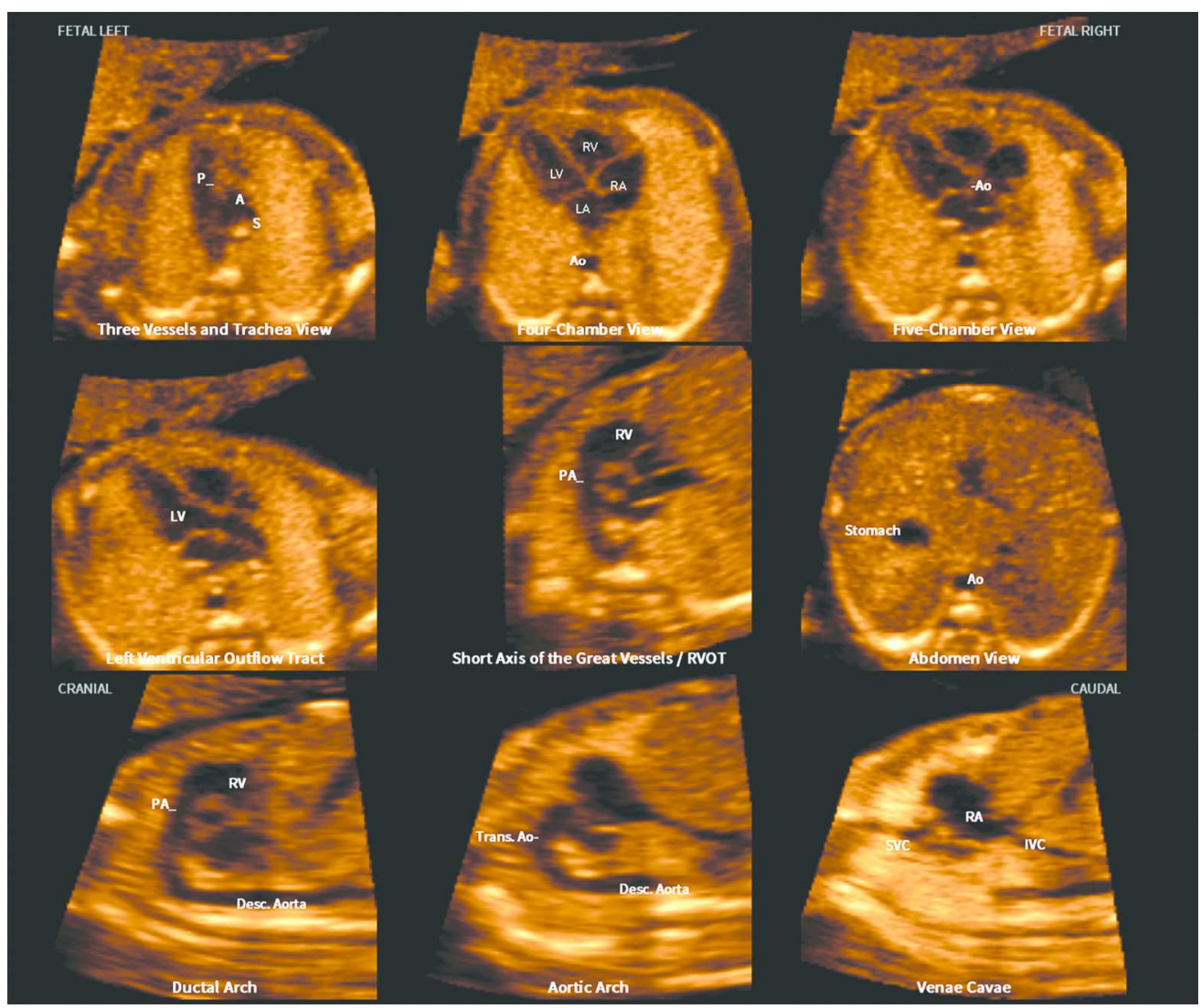

Figure 1: Application of the Fetal Intelligent Navigation Echocardiography (FINE) method to a fetus with a normal fetal heart. Nine normal cardiac diagnostic planes in a single template are shown with the unique feature of automatic labeling (through intelligent navigation) of each plane, anatomical structures, fetal left and right sides, and cranial and caudal ends (also see Video 1 ). The labeling is distinctive because it stays with the corresponding anatomical structure(s), even as the image is increased or decreased in size. A, transverse aortic arch; Ao, aorta; Desc., descending; IVC, inferior vena cava; LA, left atrium; LV, left ventricle; $\mathrm{P}$, pulmonary artery; PA, pulmonary artery; RA, right atrium; RV, right ventricle; RVOT, right ventricular outflow tract; S, superior vena cava; SVC, superior vena cava; Trans., transverse



$137 \times 114 \mathrm{~mm}(300 \times 300$ DPI $)$ 




Figure 2: Application of the FINE method to a fetus with tetralogy of Fallot at 23 weeks of gestation

(diagnostic planes or VIS-Assistance with automatic labeling are shown) (also see Video 2). Six echocardiography views were abnormal and demonstrate the typical features of this cardiac defect. The three vessels and trachea view shows a narrow pulmonary artery due to stenosis, while the transverse aortic arch is prominent. There is a 'Y-shaped' appearance of the great vessels. As is commonly noted in conotruncal abnormalities, the four-chamber view appeared normal in the diagnostic plane; however, VISAssistance demonstrates a large ventricular septal defect (not shown here). The five-chamber view shows a ventricular septal defect. The left ventricular outflow tract view shows an overriding aorta, dilated aortic root, and ventricular septal defect. In the short axis view of great vessels/right ventricular outflow tract (obtained via VIS-Assistance), the pulmonary artery is narrow with a tortuous ductus arteriosus. There is difficulty in visualizing a normal ductal arch. In the aortic arch view, the aortic root is dilated and there is a prominent ascending aorta. A, transverse aortic arch; Ao, aorta; Desc., descending; IVC, inferior vena cava; LA, left atrium; LV, left ventricle; P, pulmonary artery; PA, pulmonary artery; RA, right atrium; RV, right ventricle; RVOT, right ventricular outflow tract; S, superior vena cava; SVC, superior vena cava; Trans., transverse

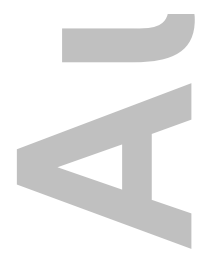

$140 \times 119 \mathrm{~mm}(300 \times 300 \mathrm{DPI})$ 


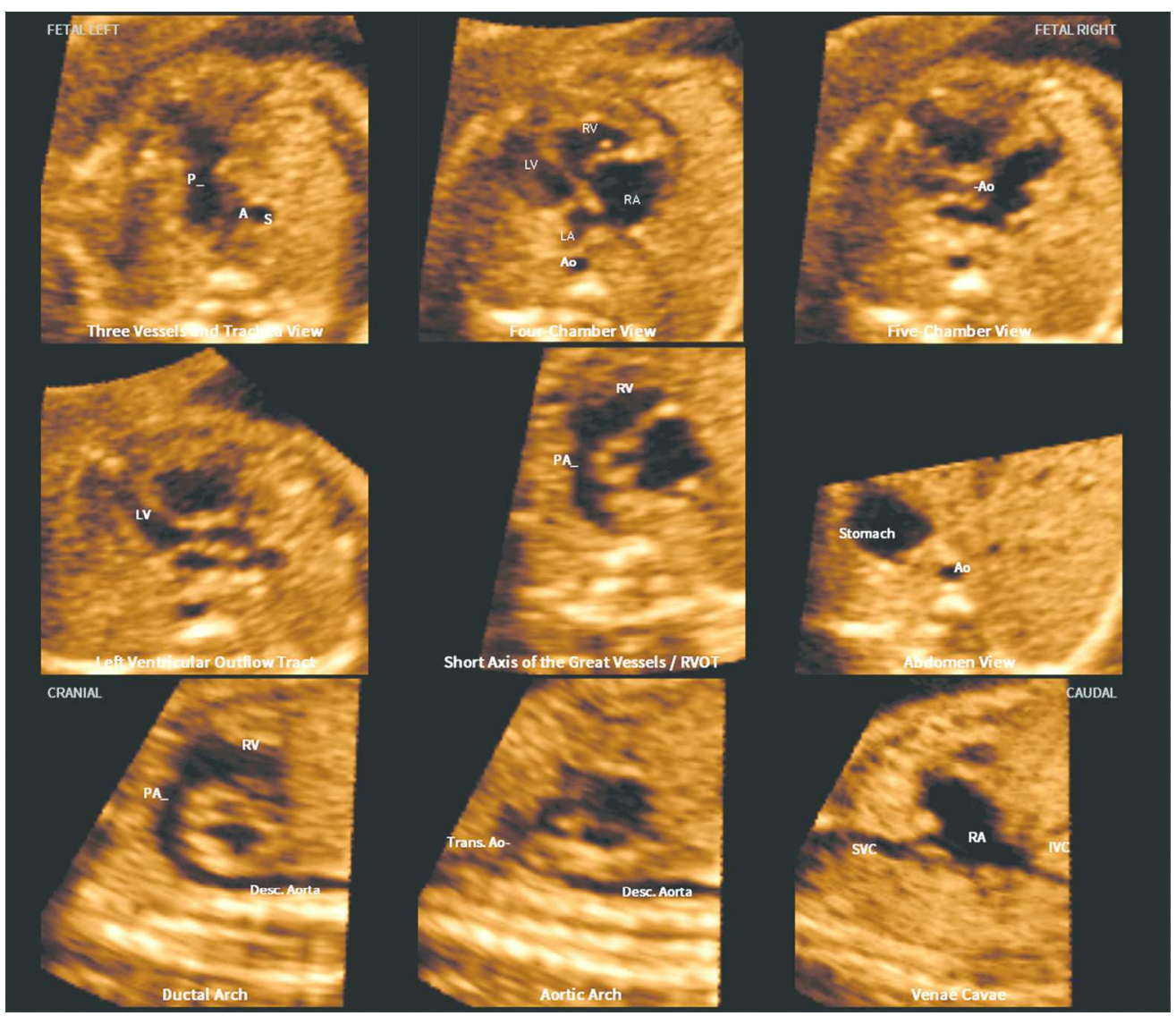

Figure 3: Application of the FINE method to a fetus with coarctation of the aorta at 24 weeks of gestation (diagnostic planes or VIS-Assistance with automatic labeling are shown) (also see Video 3). Seven echocardiography views are abnormal. The three vessels and trachea view shows a narrow transverse aortic arch. In the four-chamber view, the left side of the heart is smaller than the right side; however, the left ventricle is apex-forming. The right side of the heart appears enlarged, with the right ventricle being moderately dilated and hypertrophied. The five-chamber view shows similar findings to that of the fourchamber view. In addition, there is a narrow aortic root. The left ventricular outflow tract view shows a narrow aorta (obtained via VIS-Assistance). In the short-axis view of great vessels/right ventricular outflow tract, the cross-section of the aorta is small compared to the pulmonary artery. The enlarged right atrium is apparent. The ductal arch view demonstrates that the cross-section of the aorta is small compared to the pulmonary artery. In the aortic arch view, the coarctation is demonstrated as hypoplasia and narrowing of the transverse aortic arch as well as in the isthmus region. $\mathrm{A}$, transverse aortic arch; Ao, aorta; Desc., descending; IVC, inferior vena cava; LA, left atrium; LV, left ventricle; P, pulmonary artery; PA, pulmonary artery; RA, right atrium; RV, right ventricle; RVOT, right ventricular outflow tract; S, superior vena cava; SVC, superior vena cava; Trans., transverse



$141 \times 121 \mathrm{~mm}(300 \times 300 \mathrm{DPI})$ 


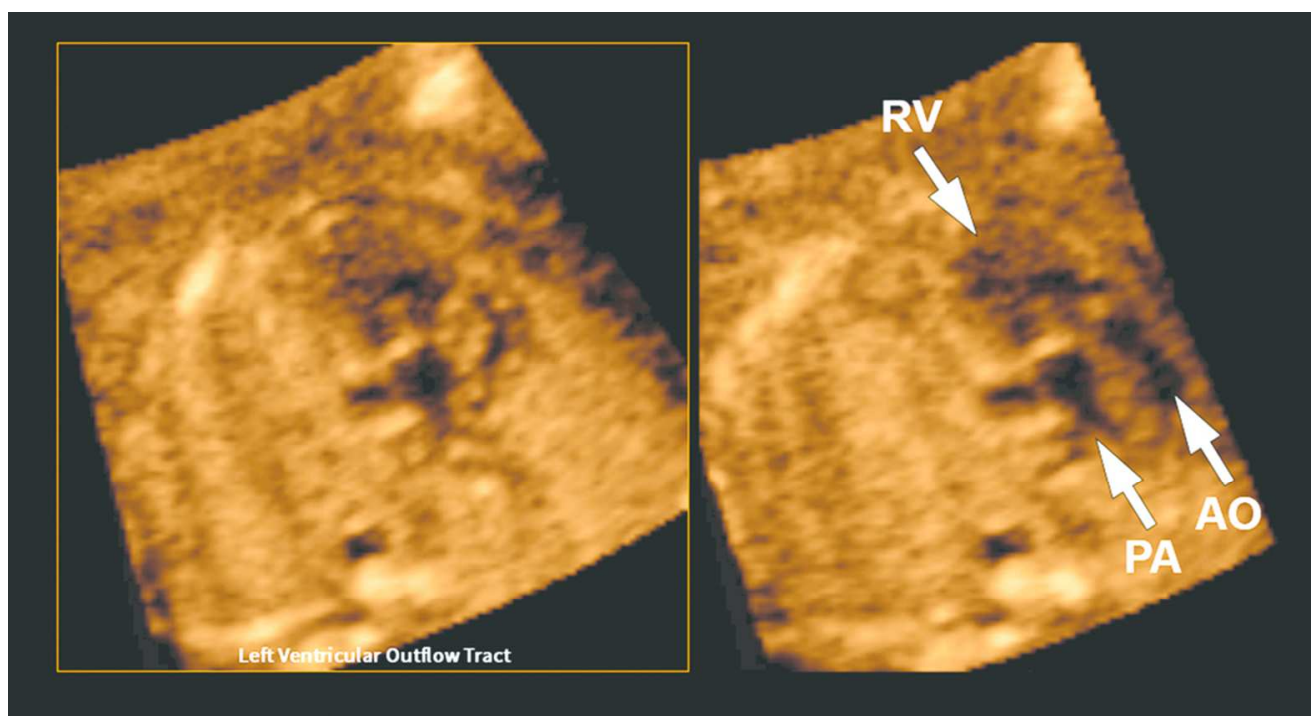

Figure 4: VIS-Assistance of the left ventricular outflow tract view in a 19 week fetus with hypoplastic left heart, double outlet right ventricle, transposition of the great vessels, and fetal stomach on the right side (also see Video 4). The abnormal diagnostic plane (left panel) demonstrates a single vessel arising from the right ventricle that is consistent with the pulmonary artery due to its bifurcation. A second vessel could not be clearly identified. However, when VIS-Assistance is activated (right panel), automatic navigational movements now demonstrate a second vessel (aorta) which is rightward and anterior, and exiting the right ventricle. These two vessels are parallel and side-by-side, consistent with transposition. AO, aorta; PA, pulmonary artery; RV, right ventricle.

$89 \times 48 \mathrm{~mm}(300 \times 300$ DPI $)$ 